\title{
Research Progress in Tidal Current Energy Power Generation Device
}

$$
\text { Yongding Wang }{ }^{1, a} \text {, Haoyang } \mathrm{Lu}^{2, \mathrm{~b}}
$$

${ }^{1}$ College of Engineering Science \& Technology, Shanghai Ocean University, Shanghai, China

${ }^{2}$ College of Engineering Science \& Technology, Shanghai Ocean University, Shanghai, China

aydwang@shou.edu.cn, ${ }^{\mathrm{b}} \mathrm{lu}$ _haoyang@126.com

Keywords: tidal current energy; turbine; progress; related technical problems

\begin{abstract}
Energy shortage and environment pollutes aggravate ceaselessly all over the world. As a green clean pollution-free renewable energy, tidal current energy has characteristics such as large reserves, wide distribution, predictability, little environmental pollution, etc. Development and utilization of tidal energy has important practical significance to ease the energy shortage and reduce the pollution of the environment. The western developed countries take the leading position in tidal current energy utilization, having entered early stage of commercialize. In this paper, the state of exploiting tidal current energy, the development of tidal current power generation and the related technical problems in tidal current energy development were introduced. The technical characteristics of different turbines were compared. Based on the technology and application comparative study, some suggests are given to the tidal current energy development and utilization in China.
\end{abstract}

\section{Introduction}

The tidal current energy is non-polluting, renewable and abundant which has been widespread concern in the international community. According to the survey, the theoretical reserves of the world's ocean energy resource is up to $766000 \mathrm{GW}[1]$ so that the development here has the attractive prospects.. There are many types of marine energy, including offshore wind energy, tidal energy, thermal energy, salinity gradient energy, etc. The tidal energy can be an important part of them and developed fast. Generally speaking, the tidal energy can be concentrated in strait, narrow waterway and entrance of gulf.

According to UNESCO estimate, there are more than 300 million kW's tidal energy can be developed and utilized in the worldwide. Non-nuclear energy projects supported by the EU estimated that the available tidal current energy could reach $12.5 \mathrm{GW}$ in Europe. China is one of the most abundant areas of tidal energy resources, Ocean Energy Resources in China's Coastal Areas points out the average power of 130 Chinese coastal waterways is about $14 \mathrm{GW}$ in theory. The theoretical average power of 37 Zhejiang coastal waterways is $7.09 \mathrm{GW}$, accounting for 41.9 percent of total national tidal current energy .Fujian, Shandong coastal reserves are also considerable.

\section{The Status of Developing Tidal Current Energy}

The western developed countries take the leading position in tidal current energy utilization The United States is one of the first countries in the world to study the tidal current energy. In 1973, Americans designed a tidal current power generation device called "Coriolis", which was mounted in Florida Sea to generate electricity. It was a pipe shaped water turbine generator, the length of pipe was $110 \mathrm{~m}$, and the diameter of pipe was $170 \mathrm{~m}$. The device was placed at $30 \mathrm{~m}$ below the surface. According to the test, when the current velocity was $2.3 \mathrm{~m} / \mathrm{s}$, the generation capacity could be reached 83MW. From then on, the tidal current energy development had entered a fast lane. The development process of tidal current energy technology can be divided into three stages: the first stage is a theoretical and laboratory research stage; Stage 2 is the practical application; Stage 3 is the industrialization of commercial operation stage.

China is one of the countries where the tidal current energy is developed early, but due to the 
financial and technical conditions, China's development is slow. China's level is still in the pilot phase of a hundred kilowatts of power generation equipment; there is a large gap with international advanced level.

In addition to the above research project, the Three Gorges of the Yangtze River group plans to build a tidal current power station (with the total installed capacity of 105MW) near Taohua Island in Zhoushan waters, Zhejiang province.

At present, China has developed the technology based on institutions and universities, but the government hasn't a large appropriation to invest the undercapitalized institutions. The researchers are hard to develop a megawatt's tidal current energy generation device. To solve these problems, we should increase investment to the scientific planning. Increasing the budget for advanced scientific research may yield technological breakthroughs. At the same time, it is good for its commercial development.

\section{Progress of Tidal Energy Power Generation Device}

Tidal energy power generation device is the core part of tidal power plant, which is directly related to the tidal current energy's benefit. The design of tidal current energy power generation device comes from wind power, especially off-shore wind power device. Some people consider it to be a "wind power generation system fixed in the bottom of the sea". After decades of research, it puts forward 20 different devices [2] which can be roughly divided into the following categories according to the structure, as shown in Figure 1.

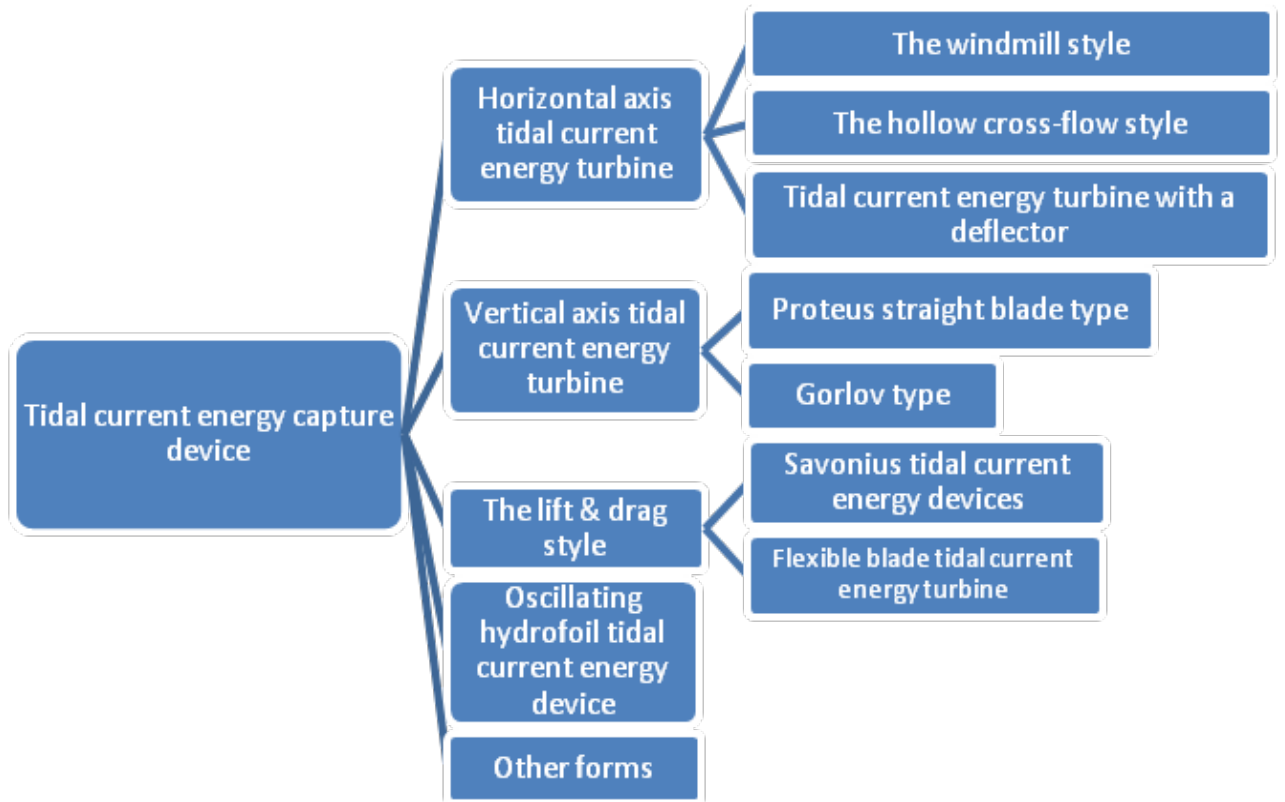

Fig.1 tidal current energy capture device

In the existing tidal energy development projects, horizontal axis tidal current energy turbine projects accounted for $43 \%$, using the vertical axis turbine projects accounted for $33 \%$ [3]. Through the test of practice, the two power generation technologies are relatively mature.

The horizontal axis tidal current energy turbine technology is mature and fastest-growing. According to the structure, it can be divided into the windmill style, the hollow cross-flow style and the deflector style. Windmill tidal current energy turbines have two more classic models are "SeaFlow" and "SeaGen" turbine made by MCT, the former is rated at $300 \mathrm{~kW}$, the latter is currently one of the biggest tidal current energy turbines used in commercial operation in the world, which is rated up to 1.2MW[4]. The structure type showed in Figure 2(a) \& 2(b). 


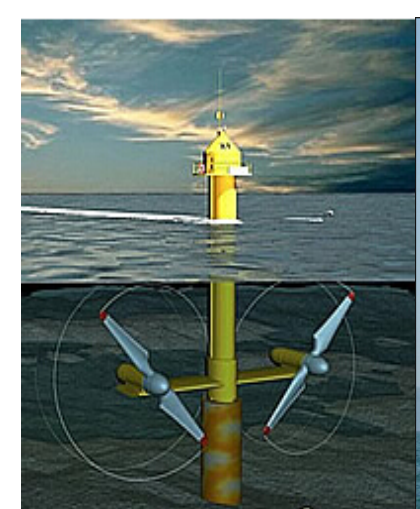

(a)

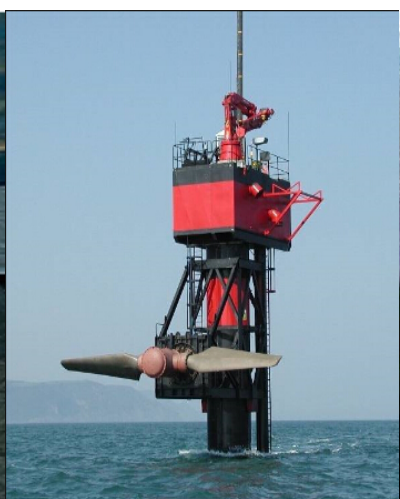

(b)

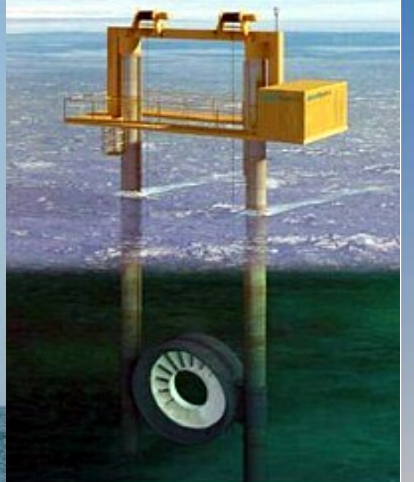

(c)

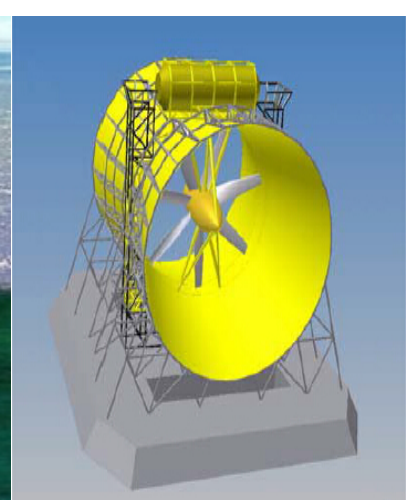

(d)

Fig.2 SeaFlow/ SeaGen/ the hollow tubular turbine/ the turbine with deflector

The hollow tubular tidal current energy turbine is a representative product developed by Irish Open Hydro Company. Its structure type showed in Figure2(c). Lunar Enemy Company and Underwater Kite (UEK) Company develop a tidal current energy turbine with a deflector, and the deflector is fixed to the outside of the impeller which can guide the flow, so as to improve the efficiency of turbine. The structure type shown in Figure2 (d)

The vertical axis tidal current energy turbines and vertical axis wind turbine are similar; the direction of water flow is vertical to the direction of blade rotating shaft. The vertical axis tidal current energy device has two kinds of turbines, the straight blade turbine and the spiral blade turbine. The vertical axis tidal current energy turbines can be started at any flow direction.

Vertical axis tidal turbine can be represented by two machines, the first one is Proteus straight blade type flow turbine designed Neptune renewable energy company, the second one is a Gorlov type spiral vane flow turbine designed by GHT. The structure type shown in Figure 3
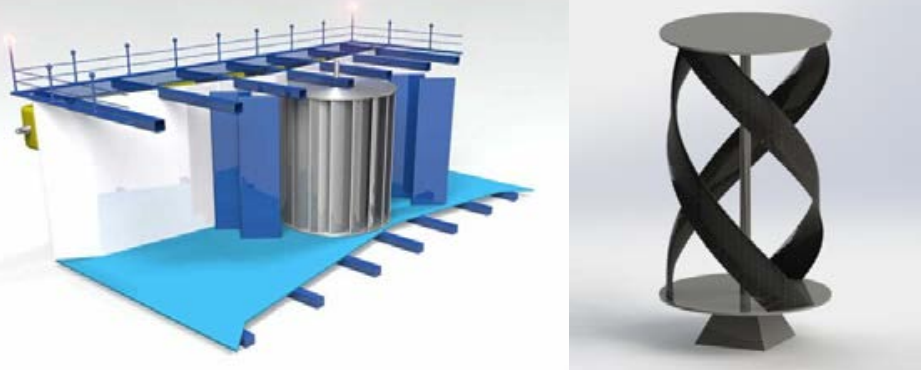

Fig.3 The Proteus and Gorlov turbine

In addition to horizontal axis tidal current turbine and vertical axis tidal current turbine, domestic and foreign researchers have proposed many other types of tidal current energy generation device. The introduction is as follows.

(1) Oscillating hydrofoil tidal current energy device is represented by the "Stingray" designed by EB Company, as shown in Figure 4. The main working part of the oscillating hydrofoil tidal current energy device is hydrofoil which is connected on the turbine through the main arm. When the water flows, the hydrofoils will lift up, causing the main arm swing up and down. This action makes the mechanical energy into electrical energy.

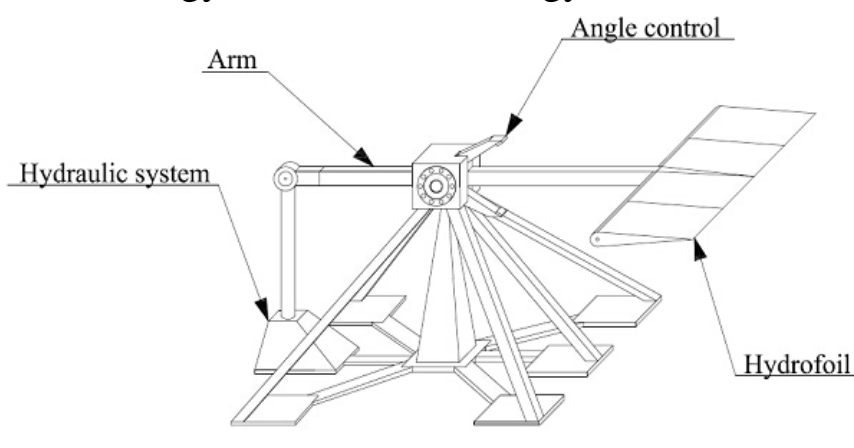

Fig.4 the Stingray turbine

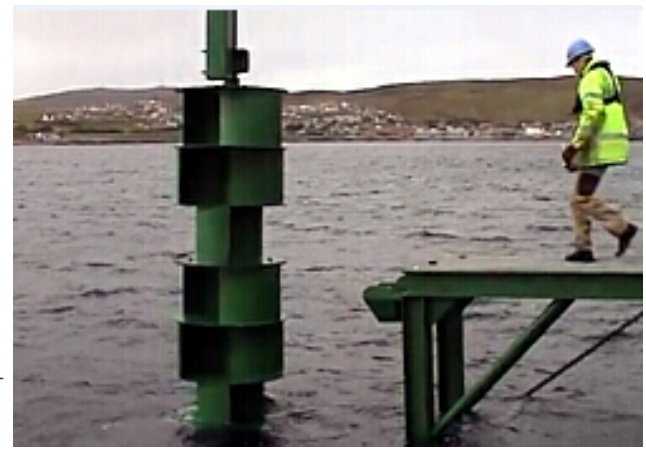

Fig.5 the savonius turbine 
(2) Savonius tidal current energy device. It is represented by the "EXIM" designed by Seapower Company. It is a resistance-type turbine with S-shaped blade. As shown in Figure 5.

(3) Flexible blade tidal current energy turbine and tidal current energy turbines with chain structure. This machine is developed jointly by the Ocean University of China and Chinese Mechanical Science Academy [5]. As shown in Figure 6. Atlantis Resources Company in Singapore designs a tidal current energy turbines with chain structure called Nereus, whose blade is arranged in a chain structure with certain angle. When water flows, the chain drives the generator which produces electricity. As shown in Figure 7.

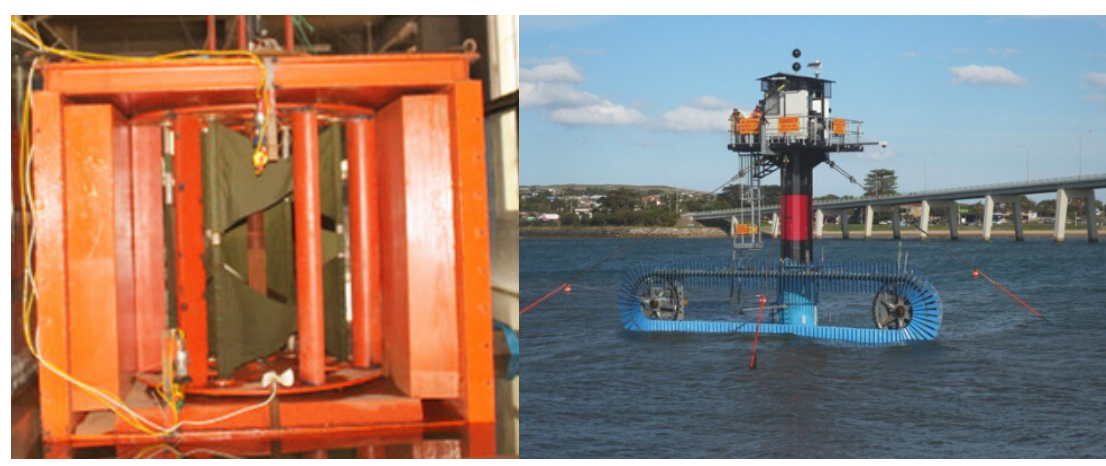

Fig.6 Flexible blade turbine

Fig.7 Nereus turbine

\section{The Proposals and Analysis of Developing Tidal Current Energy}

Tidal current energy electricity generation is an extremely complex system engineering, which involves marine engineering, civil engineering, mechanical and electrical engineering and other disciplines. Although the trend of energy generation technology is developing rapidly in recent years, but there is a large gap from commercial operation, in which several key technical problems to overcome.

Hydrodynamic analysis of tidal current energy turbine. Tidal current energy turbine consists mainly of power generation equipment and infrastructure; generators are fixed to the seabed through infrastructure. The turbine will be affected by wind, wave, flow when working, the hydrodynamic performance of the turbine is very important, because it is related to the working stability and safety. The working mechanism of the hydraulic turbine is similar to off-shore wind power device. When the researchers analyze the performance of the turbine, they can refer to the analysis technology of off-shore wind power device dynamic, which is mature.

Researchers generally use the physical model test method and CFD (Computational Fluid Dynamics) to study the dynamic performance of off-shore wind power device. Through the physical model tests in the power pool, researchers can study the different types of turbine generator, the optimization of hydraulic turbine's distribution, the performance of the deflector fixed on the turbine. With CFD technology, researchers can study the fatigue property and the dynamic property of the device in the wind, waves, and flow. Physical model tests and CFD technology can effectively improve the efficiency and accuracy.

The multi energy complementary system. Ocean energy power generation is unstable and difficult to connect to the power grid. Although the tidal current energy is more stable than wind energy, wave energy, there are many problems. For example, the flow velocity is larger at rising and falling tide, smaller in the remaining period, the flow direction changes too fast, etc. To solve these problems, researchers have proposed a multi-energy complementary technologies, including wind power-wave power systems, tidal energy-wave energy, wind energy-wave energy-solar system ${ }^{[7-10]}$. As shown in figure 11.Although the research is still in the conceptual stage, but it points out the direction for comprehensive development of marine energy.

\section{Summations and suggestions}

In summary, the tidal current energy has been developed rapidly as a new energy, which attracted 
the attention of the world. After decades of development, the tidal current energy utilization technology is relatively mature, the researchers has made nearly 20 kinds of tidal current energy power plant to meet the different sea conditions. Meanwhile, engineer encountered a series of problems in the test or project, such as structural stability under bad sea conditions, generating instability, erosion problems. These issues must be addressed before large-scale commercialization. Based on the technology and application comparative study, some suggests are given to the tidal current energy development and utilization in China.

(1)China tidal current energy resources are more concentrated, centralized funds should focus on technology; accelerate the development of key areas, to avoid duplication. For hydro turbine generating unit, the horizontal axis turbine and vertical axis turbine have matured after inspection of foreign projects. Pile-column foundation is generally applicable to the soft seabed, such as Bohai, the East China Sea and other waters of the Liaodong Bay.

(2)China will give priority to the introduction of advanced foreign technology, management expertise and professionals.

(3)The government should formulate the national medium and long-term plan for the tidal current energy resource development and make less impact on shipping. What is more, the government should encourage private capital to participate in the development of tidal current energy resources.

\section{Acknowledgements}

This work was financially supported by Special Fund for Science and Technology Commission of Shanghai Municipality innovation action plan (13dz1203701) and Special Fund for Key Project of Shanghai Municipality Agricultural Science Research (2014) No.6-3.

\section{References}

[1] China Association for Science and Technology, China Energy Research Society. The development report of energy science and technology [R].Beijing: China Science and Technology Press, 2008.

[2] Dai Qingzhong. Generate using the tidal current energy and the generation device [J].Oriental Motor, 2010(2):51-66

[3] M J Khan, G Bhuyan, M T Iqbal, et al. Hydrokinetic energy conversion systems and assessment of horizontal and vertical axis turbines for river and tidal applications: A technology status review [J].Applied Energy, 2009, 86:1823-1835.

[4] Information on http://www.buch-der-synergie.de/c_neu_html/c_06_05_wasser_gezeiten.htm (March 22, 2015)

[5] Wang Shujie. Study on hydrodynamic performances of a tidal current energy conversion device with flexible blade turbine [D].Qingdao: Ocean University of China,2009.

[6] Alessandro Schnborn, Matthew Chantzidakis. Development of a hydraulic control mechanism for cyclic pitch marine current turbines [J].Renewable Energy, 2007(32):662-679.

[7] Shao Meng. Research and application of overall development program for hybrid marine energy intelligent power supply system [D].Qingdao: Ocean University of China, 2012.

[8] Xiong Yan, Wang Haifeng, Cui Lin, et a1.Study on power generation design of stand-alone hybrid power system in Daguan island [J].Ocean Technology , 2009 , 28(1):101-103

[9] Lund H.Large-scale integration of optimal combinations of PV , wind and wave power into the electricity supply [J].Renewable Energy 2006,31(4):503-515.

[10] Wang Kunlin, You Yage, Zhang Yaqun. Energy management system of renewable stand alone energy power generation system in an island [J]. Journal of Modern Power Systems and Clean Energy,2010,34(14):13-17. 